\title{
The Use of Monoclonal Antibody (Rituximab) in the Treatment of Type II Mixed Cryoglobulinemia
}

\author{
Thiago Carlos Gonçalves Rego, Celso Mitsushi Massumoto, Rodrigo Siqueira Batista, \\ Larissa Hanauer de Moura, Lygia Maria Costa Soares and Andréia Patrícia Gomes \\ Oncology Departament, Sírio Libanês Hospital; São Paulo, SP, Brazil
}

\begin{abstract}
Anti-CD20 monoclonal antibody has been successfully used to treat several self-immune diseases. The authors report the case of a 71 year-old female patient under the use of pegylated form of interferon á associated with ribavirin for the treatment of hepatitis $C$, who, after concluding the therapeutic program - negative Polymerase Chain Reaction (PCR) - developed a severe cutaneous vasculitis, receiving the diagnostic of type II mixed cryoglobulinemia. Four sessions of plasmapheresis were prescribed along the period of 11 days, with no result. The choice made was to administer anti-CD 20 monoclonal antibody (rituximab), $375 \mathrm{mg} / \mathrm{m}^{2}$, per week, during four consecutive weeks. One could observe fast recovery from the purpura, as well as total remission of urticaria. Key-Words: Anti-CD 20 monoclonal, type II mixed cryoglobulinemia, hepatitis C, Hodgkin's disease.
\end{abstract}

Cryoglobulins are immunoglobulins that at low temperature, $\left(4^{\circ} \mathrm{C}\right)$ in vitro, have the property of forming precipitates, which at normal body temperature $\left(37^{\circ} \mathrm{C}\right)$ are dissolved. There are three described types of cryoglobulinemia: (1) Type I - monoclonal proteins that lack rheumatoid factor active, (2) Type II, mixed - monoclonal antibody with rheumatoid factor active, and (3) Type III polyclonal antibody with rheumatoid factor active [1]. Type II is the most frequently associated with vasculitis [2].

Vasculitis secondary to cryoglobulinemia occurs in only a small minority of patients with cryoglobulins in their serum, but this diagnosis should be considered when patients present palpable purpura, especially when recurrent, and peripheral neuropathy [3].

Type II cryoglobulinemia can be essential (idiopathic) or secondary to infections, inflammatory or neoplasic processes [4]. Nowadays, hepatitis $C$ can be pointed as the main cause of type II mixed cryoglobulinemia, followed by hepatitis B, systemic lupus erythematosus, rheumatoid arthritis and the B cells non-Hodgkin's lymphoma [5,6]. The disease can be treated at three different levels: (1) etiologic, (2) pathogenic, or (3) symptomatic.

The elimination of hepatitis $C$ virus is obtained by combining interferon and ribavirin in a minority of cases only. Whenever there are severe complications, like glomerulonephritis, neuropathy or vasculitis, it will be treated by an association of corticoids, plasmapheresis and cyclophosphamide, however these immunosuppressive agents may facilitate viral replication [7]. More recently, a pathogenic treatment with rituximab - an anti-CD 20 monoclonal antibody present in B Cells - has been proposed for hepatitis C Virus infected patients with type II mixed cryoglobulinemia [8,9].

Received on 10 October 2006; revised 28 November 2006. Address for correspondence: Dr. Thiago Carlos Gonçalves Rego. Av. Oliveira Botelho, 87 BL 2 AP 501 B Alto. Zip Code: 25961-143. Teresópolis-RJ, Brazil. Phone: (55 21) 2642-2732. E-mail: regothiago@yahoo.com.br.

The Brazilian Journal of Infectious Diseases 2007;11(1):174-175. (C) 2007 by The Brazilian Journal of Infectious Diseases and Contexto Publishing. All rights reserved.
It is the scope of the present article to report a case illustrating this therapeutic innovation.

\section{Case Report}

Female patient, 71 year-old, hepatitis $C$ virus infected reports that twenty (20) months earlier (before beginning of anti-viral therapeutic) had noticed disseminated cutaneous lesions, of progressive course, some pruriginous, predominantly located on the lower limbs. Having made use of peg-interferon and ribavirin for the hepatitis $\mathrm{C}$ during twelve (12) months, presently, seven (7) months after end of treatment, the patient is showing sustained virological response, as identified by Polymerase Chain Reaction (PCR). After conclusion of the treatment against the virus, the patient suffers severe aggravation of cutaneous condition and searches for medical care.

The patient presents previous history of Hodgkin's disease - mixed cellularity stage IIB -, then treated with four cycles of adriamycin, bleomicin, vinblastine, dacarbazine and involved field radiotherapy, and currently shows Hodgkin's disease in total remission, as evaluated by Positron emission tomography and PCR respectively.

Physical examination evidenced cutaneous lesions palpable purpura and urticaria - of several sizes, diffusely distributed, but predominant on lower limbs and buttocks. Laboratorial investigation confirmed the diagnostic - type II cryoglobulinemia, $660 \mathrm{micro} / \mathrm{mL}$. Four sessions of plasmapheresis were prescribed along eleven (11) days to control the symptoms, after which cryoglobulinemia showed values of $757 \mathrm{micro} / \mathrm{mL}$. Refractoriness to treatment led to the decision of trying rituximab, $375 \mathrm{mg} / \mathrm{m}^{2}$, during four consecutives weeks, with fast response from urticaria and only some purpura left on lower limb.

Type II mixed cryoglobulinemia has not suffered significant modification. After four months of treatment the patient maintains sustained virological response and a stable condition.

\section{Discussion}

Rituximab is a monoclonal antibody directed against the antigen CD 20, a molecule present on the surface of B pre- 
lymphocyte, activated or not. It is a drug of low toxicity, only tremors and shivering being reported by a minority of patients. No significant rise in the incidence of infections is described among rituximab users.

The decision of trying rituximab for the treatment of type II mixed cryoglobulinemia was due to the pathogenesis of the disease, associated with the presence of cryoglobulins (immunoglobulins), molecules produced by B lymphocytes [10], wich would have their level reduced with the adoption of a monoclonal antibody directed to these cells (anti-CD20). Thus the drug can be used by patients with type II mixed cryoglobulinemia resistant to the conventional therapeutic, as well as in the more severe forms of the disease.

The patient in the present report being non-responsive to plasmapheresis, benefited enormously from the use of antiCD20 antibody, showing evident improved condition concerning vasculitis syndrome.

The favorable result here reported shall motivate further investigation to establish the role of rituximab in the treatment of type II mixed cryoglobulinemia.

\section{References}

1. Morra E. Cryoglobulinemia. Hematology 2005;368-72.

2. Ferri C., et al. Mixed cryoglobulinemia: demographic, clinical and serologic features and survival in 231 patients. Semin Arthritis Rheum 2004;33:355.

3. Della Rossa A., et al: Treatment of chronic hepatitis C infection with cryoglobulinemia. Curr Opin Rheumatol 2002;13:231.

4. Limal N., Cacoub P. Hepatitis C virus-associated extrahepatic manifestations: a review. Metab Brain Dis 2004;19(3-4):357-81.

5. Giordano N., Amendola A., Papakostas P., et al. Immune and autoimmune disorders in HCV chronic liver disease: Personal experience and commentary on literature. New Microbiol 2005;28(4):311-7.

6. Palekar N.A., Harrison S.A. Extrahepatic manifestations of hepatitis C. South Med J 1998;10:1019-23.

7. Meyers C.M., et al. Hepatitis C and renal disease: an update. Am J Kidney Dis 2003;42:631.

8. Basse G., Ribes D., Kamar N., et al. Rituximab therapy for the novo mixed cryoglobulinemia in renal transplant patients. Transplantation 2005;80(11):1560-4.

9. Mascia M.T., Puccini R., Ferri C. Manifestazioni autoimmune e linfoproliferaive HCV-correlate: l'esempio della cryoglobulinemia mista. Ital nephrol 2004;21(3):225-37.

10. Siqueira-Batista R., Quintas L.E.M., Oliveira F.S.O., et al. Scientia Immunis I. Aspectos históricos, filogenia e organização do sistema imunológico. Clin Ped 1995;19(3):14-32. 